УДК 330.34

\title{
ЭВОЛЮЦИЯ ПОНЯТИЯ «УСТОЙЧИВОЕ РАЗВИТИЕ» В ЭКОНОМИЧЕСКОЙ НАУКЕ
}

\author{
О.М. МАЗУРЕНКО \\ магистр экономических наук, лаборант кафедры «Экономика и право», \\ Белорусский национальный технический университет, г. Минск
}

\begin{abstract}
Аннотация
В статье изложены основные теоретические подходы к трактовке понятия «устойчивое развитие», определень особенности его формирования и развития.
\end{abstract}

Abstract

The article describes the main theoretical approaches to the interpretation of the concept of "sustainable development", defined features of its formation and development.

\section{ВВЕДЕНИЕ}

Последние десятилетия показали, что биосфера Земли в целом и её отдельные составляющие - экосистемы различных уровней - обладают ограниченными возможностями для обеспечения своего нормального функционирования и воспроизводства в условиях чрезмерного воздействия человеческой деятельности.

До 1970-х гг. экологические проблемы редко включались в повестку дня международного сообщества, основное внимание уделялось проблемам эксплуатации и использования природных ресурсов, стремясь, в частности, к тому, чтобы развивающиеся страны, осуществляли контроль над своими ресурсами. В течение 1960-х гг. был заключен ряд соглашений по проблеме загрязнения морей, особенно в результате разлива нефти. С тех пор по мере появления все новых свидетельств ухудшения окружающей среды в глобальном масштабе росла обеспокоенность международного сообщества в связи с влиянием развития на экологию планеты и благополучие человека. Организация Объединенных Наций выступала как основной выразитель озабоченности по поводу состояния окружающей среды и главный сторонник «устойчивого развития». [1]

Понятие «устойчивое развитие» имеет большое множество определений, каждое из которых вносит вклад в конкретизацию этого термина. Отсутствие единства мнений в определении и трактовки этого термина объясняется как сложностью самого понятия, включающего социальные, экономические и экологические аспекты развития человечества, так и несовпадением взглядов представителей разных слоев общества - научных, политических, предпринимательских. [2]

\section{РЕЗУЛЬТАТЫ И ИХ ОБСУЖДЕНИЕ}

Идеи создания идеальной модели существования общества существовали уже в эпоху античности. Одна из основных тем учения Платона (428/7 г. до н. э.- 347 г. до н. э.) - идея устройства «идеального» или «справедливого» государства (360 г. до н. э.). «Политика» (335 - 322 до н. э) Аристотеля, ученика Платона, представляет собой трактат, который содержит начала социальной и политической философии, политологии и теории управления.

Работы Т. Мора «Утопия» (1516 г.) и Т. Кампанеллы «Город Солнца» (1602 г.). посвящены описанию идеального государства, построенного на принципах справедливости и способствующих стабильному развитию общества.

Вторая половина 18 века ознаменована промышленной революцией в Англии. Использование машин в труде приводит к многократному приумножению возможностей человека и, как следствие, к многократному усилению воздействия человека на окружающую среду. Увеличение возможностей человека приводит к возникновению идеи о неограниченном экономическом росте.

В своём труде «Эссе о принципах народонаселения» (1798 г.) английский учёный, священник Т.Мальтус ставит под сомнение безграничность человеческого развития: численность людей растёт в геометрической прогрессии, тогда, при одновременном арифметическом росте средств существования. Из этого следует, что рост численности народонаселения будет сдерживаться постоянными войнами, эпидемиями и голодом. Т. Мальтусом было положено начало теории об ограниченности природных ресурсов, однако его идеи опередили своё время и им не было уделено соответствующее внимание.

Период конца 19 - начало 20 вв. характеризуется становлением термина и теории «Ноосферы». Термин «ноосфера» предложен французским учёным Э. Леруа, теория ноосферы развита русским учёным В.И.Вернадским. Теория ноосферы описывает тесное взаимодействие человека и природы, в котором человек является частью природы.

Несмотря на усиление внимания учёных к проблемам взаимоотношений человека и природы, антропогенная нагрузка на природные экосистемы продолжает увеличиваться. Стремительный рост народонаселения, рождение и развитие атомной промышленности, «зелёная революция», попытка достижения сверхприбыли становятся причиной катастрофической переэксплуатации природных ресурсов. Все более очевидным становится негативное воздействие на окружающую. 
Формирование концепции устойчивого развития явилось логическим переходом от экологизации научных знаний и социально-экономического развития, бурно начавшимся в1970-е гг.

В 1970-е гг. начинается формирование различных организаций, движений и программ, так или иначе связанных с защитой природных ресурсов. В 1970 году основан Совет по защите природных ресурсов с целью достижения полноты экологической политики США. В этом же году проведен Первый день Земли в форме национального семинара по защите окружающей среды.

«Римский клуб» инициирует и спонсирует первые исследования, посвящённые глобальной проблематике человеческого развития. Авторами исследования становятся американские учёные Джей Форрестер и Деннис Медоуз. Для изучения долгосрочных тенденций мирового развития, они впервые в истории применили компьютерное моделирование. Под руководством Дж. Форрестера появились математические модели «Мир-1» и «Мир-2». Результаты, полученные в ходе исследований данных моделей, легли в основу книги Дж. Форрестера «Мировая динамика», которая была опубликована в 1971 году. Модель Д. Л. Медоуза «Мир-3» является продолжением модели Дж. Форрестера «Мир-2». 12 марта 1972 года в Вашингтоне, в Смитсоновском институте, публике был представлен доклад Римского клуба «Пределы роста», содержащий выводы, полученные с помощью данной модели, суть которых заключаются в том, что при сохранении нынешних тенденций к росту в условиях ограниченной по своим масштабам планеты уже следующие поколения человечества достигнут пределов демографического и экономического роста, что приведет мировую систему к неконтролируемому кризису и краху. «Пределы роста» вызвали резонанс в политических кругах и оказали сильное влияние на мировоззренческие взгляды многих людей. Считается, что доклад «Пределы роста» является отправной точкой не только в создании концепции устойчивого развития, но и в формировании экологически сбалансированной политики во многих государствах.

На Стокгольмской Конференцию ООН по проблемам окружающей человека среды прошедшей в июне 1972 года был впервые включен в международную повестку дня вопрос о взаимосвязи между экономическим развитием и ухудшением состояния окружающей среды. По итогам конференции была принята Декларация Конференции ООН по проблемам окружающей человека среды, которая содержала 26 принципов и план действий, включающий 109 принципов. Принципы, содержащиеся в Стокгольмской декларации по проблемам окружающей человека среды, впервые содержали свод законов по природоохранной деятельности на государственном и межправительственном уровне. Конференция в Стокгольме положила начало в развитии природоохранной политики на государственном уровне, а также природоохранного движения в мировом масштабе.

Также в декабре 1972 года учреждена Программа ООН по окружающей среде (UNEP, ЮНЕП), которая остается и сегодня ведущим учреждением в мире по проблемам окружающей среды.

В октябре 1982 года на заседании Генеральной ассамблеи ООН в Вашингтоне, принимается «Всемирная хартия природы» («The World Charter of Nature Defense»), в которой провозглашается ряд принципов сохранения природы, в соответствии с которыми должна направляться и оцениваться любая деятельность человека, затрагивающая природу. Первый из принципов Хартии гласит: «Природу необходимо уважать и не нарушать ее основные процессы».

В 1980 г. опубликован доклад «Global 2000», в котором биоразнообразие впервые признано критической характеристикой, присущей функционированию планетарной экосистемы. Двумя годами позже, опубликована Всемирная Хартия природы ООН, призывающая к пониманию зависимости человечества от природных ресурсов и необходимости контроля их добычи.

В 1983 году учреждена Международная комиссия по окружающей среде и развитию (МКОСР), основной задачей которой является разработка основных принципов, показателей устойчивого развития, а также глобальной эколого-экономической программы действий. Результатом трехлетней работы комиссии явился доклад «Наше общее будущее», в котором впервые даны направления к решению глобальных проблем на основе учета всех экологического, экономического и социального аспектов.

В 1990 году в Канаде учрежден Международный институт устойчивого развития. В 1990-х гг. проведено множество мероприятий, касающихся отдельных аспектов устойчивого развития: Саммит ООН по проблеме детей (1990г.), Всемирный саммит по социальному развитию (1995г.), четвертая Всемирная конференция по вопросу Женщин (1995г.) и др. В этот же период формально принят как добровольный международный стандарт корпоративного экологического менеджмента ISO 14001.

В 2001 году, признавая необходимость более активно оказывать помощь беднейшим нациям, государствамичленами ООН приняты «Цели развития тысячелетия ООН» - ограничивающие во времени (2015г.) и количественно измеряемые цели для борьбы с бедностью, голодом, болезнями, безграмотностью, деградацией окружающей среды и дискриминацией женщин. В 2002 году в Йоханнесбурге проведен Всемирный саммит по устойчивому развитию, по результатам которого «сотрудничество» выдвинуто как метод достижения устойчивости. В этом же году Глобальная инициатива отчетности выпускает руководство по созданию отчетов об экономических, социальных и экологических аспектах деловой активности.

Итогом 2000-х гг., становится Копенгагенское климатическое соглашение 2009 года, одним из пунктов которого является соглашение о сдерживании странами роста глобальной температуры с помощью значительного сокращения выбросов, увеличения финансирования для начала действий по снижению выбросов в развивающихся странах.

Экономический рост приводит ко всё большей потребности учёта экологических издержек. Истощение и деградация природных ресурсов оказывают негативный эффект на социальные отношения, структуры производства и потребления. Происходит переход к экологической экономике и экономике устойчивого развития.

Впервые термин «устойчивое развитие» был применен в 1987 г. в докладе Международной комиссия ООН по окружающей среде и развитию, которую возглавила премьер-министр Норвегии Гру Харлем Брундтланд, «Наше об- 
щее будущее» был широко использован термин «sustainable development», который понимался, как модель движения вперед, при которой достигается удовлетворение жизненных потребностей нынешнего поколения людей без лишения будущих поколений такой возможности. [2]

Это определение устойчивого развития, принимается как наименее спорное из всех, однако, оно скорее отражает стратегическую цель, чем указывает конкретный путь для практических действий. В то же время устойчивое развитие относится к категории понятий, отражающих идею, которую можно сформулировать в общих чертах, но нельзя описать точными количественными категориями, что не лишает ее ни научного, ни практического смысла, а лишь умножает возможности трактовки понятия устойчивого развития. [2]

В отечественной литературе английский термин «sustainable development» был переведен как «устойчивое развитие». Такой перевод термина иногда критикуется, разные авторы уже не раз отмечали неточность русского перевода зарубежного выражения. Действительно, определение термина «устойчивое развитие» означает просто устойчивый, постоянный рост.

В то же время перевод термина с английского языка может быть следующим:

- sustainable - устойчивый, жизнеспособный; экологически рациональный , обеспечивающий учёт будущих потребностей , поддерживаемый [3]

- development - развитие, рост, совершенствование, эволюция, изложение, раскрытие, результат, предприятие, обрабатываемый участок земли, разработка, производство [4].

T.e. «sustainable development» - экологически рациональное, поддерживаемое развитие.

При этом есть авторы, отмечающие, что термин «sustainable development» было бы правильнее перевести как «экологически устойчивое экономическое развитие», поскольку «понятие устойчивого развития подразумевает переход от постановки задачи охраны природы за счет экономического роста к постановке задачи одновременного обеспечения экономического развития и охраны среды» [5].

Тем не менее термин «устойчивое развитие» хорошо прижился в русском языке и по словам Н.Н. Моисеева, речь должна идти не о его замене, а о наполнении его единообразным научно-обоснованным содержанием, о его адаптации к современному научному мировоззрению [6].

В отечественной и зарубежной литературе существует большое множество трактовок понятия устойчивого развития:

1. Доклад Комиссии Брундтланд (1987)

Устойчивое развитие - это такое развитие, которое удовлетворяет потребности настоящего времени, но не ставит под угрозу способность будущих поколений удовлетворять свои собственные потребности.

Оно включает два ключевых понятия:

- понятие потребностей, в частности потребностей, необходимых для существования беднейших слоев населения, которые должны быть предметом первостепенного приоритета;

- понятие ограничений, обусловленных состоянием технологии и организацией общества, накладываемых на способность окружающей среды удовлетворять нынешние и будущие потребности.

Задачи экономического и социального развития должны быть определены с учетом его устойчивости во всех странах - в экономически развитых или развивающихся, в странах с рыночной или плановой экономикой. Конкретные подходы к его реализации будут, безусловно, разниться, но они должны иметь некоторые общие принципиальные характеристики и исходить из консенсуса относительно основной концепции устойчивого развития и вписываться в широкую стратегию для его осуществления.

С развитием связано прогрессивное преобразование экономики и общества. Развитие, устойчивое по материальным параметрам, теоретически может иметь место даже в жестких социальных и политических рамках. Но фактически эта устойчивость может быть обеспечена лишь при условии, что при разработке политики развития уделяется внимание таким вопросам, как изменения в доступе к ресурсам и в распределении затрат и доходов между различными слоями населения. Даже при узком понимании физической устойчивости развития предусматривается забота о социальной справедливости по отношению к разным поколениям, забота, которая логически должна быть распространена на отношения справедливости к различным слоям населения в пределах каждого поколения.

2. Во Всемирной стратегии охраны природы, объявленной 5 марта 1980 г., приводится следующее определение: «...такое развитие, которое обеспечивает реальное улучшение качества жизни людей и в то же самое время сохраняет природное разнообразие Земли».

Цель Всемирной стратегии охраны природы заключается в том, чтобы помочь достижению устойчивого развития посредством сохранения жизненных ресурсов. Стратегия:

- объясняет значение сохранения жизненных ресурсов для выживания человека и устойчивого развития;

- определяет приоритет вопросов сохранения и главные требования, связанные с ними;

- предлагает эффективные пути для достижения цели стратегии.

Создатели стратегии намерены с ее помощью стимулировать более сфокусированный подход к охране жизненных ресурсов и обеспечить политическое руководство в плане ее выполнения. Стратегия концентрируется на главных проблемах, непосредственно воздействующих на достижение целей сохранения и на их взаимосвязь в процессе охраны. В частности, стратегия определяет действия, необходимые для улучшения эффективности охраны, а также интегрирует проблемы сохранения и развития.

3. «Заботясь о Земле», 1991 г. 
«Заботясь о Земле» употребляет слово «устойчивый» в нескольких вариантах, таких, как: «устойчивое развитие», «устойчивая экономика», «устойчивое общество» и «устойчивое пользование».

Термин критикуется за двусмысленность и за то, что предполагает широкий ряд интерпретаций, многие из которых противоречивы. Замешательство объясняется во многом тем, что термины «устойчивое развитие», «устойчивый рост» и «устойчивое пользование» применяются как взаимозаменяемые, как если бы их значения были одинаковыми. Это не так. Термин «устойчивый рост» внутренне противоречив: никакое физическое явление не может расти бесконечно. Термин «устойчивое пользование» применим только к возобновимым ресурсам: он означает использование их в пределах их способности к восстановлению.

Термин «устойчивое развитие», применяемый в Стратегии, означает улучшение качества человеческой жизни, не выходя за пределы несущей емкости поддерживающих экосистем.

«Устойчивая экономика» является результатом устойчивого развития. Она сохраняет свою природно-ресурсную базу. Она может продолжать развиваться, только адаптируясь, только посредством улучшения знаний, организации, технической эффективности и мудрости.

«Устойчивое общество» существует при наличии 9 принципов, выделенных в этой главе.

4. В докладе на Первой Международной Конферениии «Проблемы ноосферы и устойчивого развития» 1996 г. в Санкт-Петербург Академиком, председателем СО РАН, вище-президентом РАН Коптюгом В.А. приводится следующее определение этого понятия: «...такая модель развития общества, при которой удовлетворяются основные жизненные потребности как нынешнего, так и всех последующих поколений...».

5. Всемирный банк: «...управление совокупным капиталом общества в интересах сохранения и приумножения человеческих возможностей...».

6. Урсул А.Д. приводит следующую трактовку: «...управляемое системно-сбалансированное социоприродное развитие, не разрушающее окружающую природную среду и обеспечивающее выживание и безопасное неопределенно долгое существование цивилизации...». [7]

7. М.А. Кувшинов: «...целенаправленный процесс управления социально-экономической системой муниципального образования обеспечивающий устойчивость связей, элементов и структуры системы в целом в направлениях роста уровня качества жизни населения в рамках баланса с окружающей средой...». [8]

8. Н. Давыдова, О. Тимофеева: «...такое развитие, которое не влечет за собой необратимого изменения среды обитания человека...». [9]

9. Н.Н. Моисеев: «...реализация стратегии человека, его пути к эпохе ноосферы, то есть к состоянию коэволюции общества и природы...». [10]

10. О.С. Пчелинщев:«...переход от «экономики использования ресурсов»к экономике их системного воспроизводства...». [11]

11. А.В. Цвикилевич под устойчивым развитием понимает «...процесс, ориентированный на постоянное сохранение динамического равновесия посредством целенаправленного использования имеющегося потенциала и условий внешней среды...». [12]

Предлагаемые определения отличаются друг от друга акцентом на определенных проблемах, таких как: сохранение биоразнообразия, несущую способность окружающей природной среды, сохранение природных ресурсов, равновесие между экономической деятельностью и состоянием окружающей среды, устойчивой рост экономики, справедливые отношения между поколениями, межрегиональная справедливость, качество жизни, социальные и культурные ценности.

Важное значение приобретает сбалансированное согласование трёх аспектов устойчивого развития (экономического, социального и экологического) и реализация в этом контексте конкретных мероприятий, являющихся средствами достижения устойчивого развития, а также механизмы взаимодействия этих составляющих.

Экономический и социальные аспекты устойчивого развития, взаимодействуя друг с другом, ставят такие задачи, как достижение справедливости внутри одного поколения и оказания целенаправленной помощи бедным слоям населения.

Связь социального и экологического элементов вызывает интерес к таким вопросам, как внутрипоколенное и межпоколенное равенство, включая соблюдение прав будущих поколений и участие населения в процессе принятия решений.

Центральное место в понятии устойчивого развития занимает проблема учета долгосрочных экологических последствий принимаемых сегодня экономических решений. Механизм взаимодействия экономического и экологического элементов дал начало стоимостной оценки и учета в экономической отчетности предприятия внешних воздействий на окружающую среду. Необходима минимизация негативных экологических последствий, будущих внешних эффектов для последующих поколений. Таким образом проблема экологических ограничений, компромисса между текущим и будущим потреблением должна стать основной при разработке социально-экономической стратегии развития на длительную перспективу для любой страны.

\section{ВЫВОДЫ}

Несмотря на большое разнообразие трактовок термина, основной задачей устойчивого развития является удовлетворение человеческих потребностей и стремлений. Устойчивое развитие требует удовлетворения наиболее важных для жизни потребностей всех людей и предоставления всем возможности удовлетворять свои стремления к лучшей жизни в равной степени [8] и может быть определено как гармоничный, сбалансированный процесс изменений 
научно-технической направленности, при согласованной эксплуатации экологических ресурсов, направлении инвестиций, развитии социального капитала.

\section{ЛИТЕРАТУРА}

1. ООН и устойчивое развитие [Электронный ресурс] / Режим доступа : http://www.un.org/ru/development/sustainable/background.shtml - Дата доступа : 18.07.2015.

2. Бегун Т. В. Устойчивое развитие: определение, концепция и факторы в контексте моногородов [Текст] / Т. В. Бегун // Экономика, управление, финансы: материалы II междунар. науч. конф. (г. Пермь, декабрь 2012 г.). Пермь: Меркурий, 2012. - С. 158-163.

3. Англо-русский словарь [Электронный ресурс] / Режим доступа : http://dic.academic.ru/word/sustainable - Дата доступа : 03.07.2015.

4. Англо-русский словарь [Электронный ресурс] / Режим доступа : http://dic.academic.ru/word/development Дата доступа : 03.07.2015.

5. Угольницкий Г.А. Иерархическое управление устойчивым развитием. / Г.А. Угольницкий. - Москва: Издательство физико-математической литературы, 2010. - 336 с.

6. (Моисеев Н.Н. “Устойчивое развитие” или “Стратегия переходного периода” // План действий - “Устойчивые Нидерланды”. - М.,1995.- С.3-4).

7. Урсул А.Д. Путь в ноосферу: Концепция выживания и устойчивого развития цивилизации. - М., 1993; Он же. Становление ноосферного интеллекта и опережающее образование // Синергетика и образование. - М., 1997.

8. Кувшинов М.А. Понятие управления устойчивым развитием социально-экономической системы муниципального образования [Текст] / М.А. Кувшинов // Молодой ученый. — 2011. — № 7. Т. 1. — С. 86-91.

9. Давыдова Н., Тимофеева О. Устойчивое развитие города. Вопросы разработки стратегии // Муниципальная экономика - 2000. - № 4. - С.18-23.

10. Моисеев Н.Н. Историческое развитие и экологическое образование. - М.: Изд-во МНЭПУ, 1995.

11. Пчелинцев О.С. Региональная экономика в системе устойчивого развития. - М.: Наука, 2004. - 258c.

12. Цвикилевич, А.В. Совершенствование управление развитием муниципального образования. - "Академия Естествознания", 2006.

Статья поступила в редакциию 23 июля 2015 года. 